\title{
Papillary fibroelastoma of the pulmonary valve
}

\author{
Moheb Ibrahim MD FRCSC ${ }^{1}$, Roy G Masters MD FRCSC ${ }^{1}$, Mark Hynes MD FRCPC ${ }^{2}$, \\ John P Veinot MD FRCPC ${ }^{3}$, Ross A Davies MD FRCPC ${ }^{4}$
}

M Ibrahim, RG Masters, M Hynes, JP Veinot, RA Davies. Papillary fibroelastoma of the pulmonary valve. Can J Cardiol 2006;22(6):509-510.

There is a lack of information regarding the diagnosis and management of papillary fibroelastoma of the pulmonary valve due to the rarity of the tumour at this location. A case of pulmonary valve papillary fibroelastoma in a 60-year-old woman is reported and the approach for diagnosis and management is described.

\section{Un fibroélastome papillaire de la valvule pulmonaire}

Il manque d'information au sujet du diagnostic et de la prise en charge du fibroélastome papillaire de la valvule pulmonaire en raison de la rareté de cette tumeur dans ce foyer. Un cas de fibroélastome papillaire de la valvule pulmonaire est décrit chez une femme de 60 ans, de même que la démarche diagnostique et de prise en charge.

Key Words: Pathology; Pulmonary valve; Tumour

$\mathrm{T}$ here is a paucity of information concerning papillary fibroelastoma (PFE) of the pulmonary valve due to its rarity at this location. We describe a case along with a discussion of the diagnosis and management.

\section{CASE PRESENTATION}

A 60-year-old woman had a right superficial spreading leg melanoma removed one year before presentation. At presentation, a transthoracic echocardiogram was performed for systemic hypertension and revealed a $1 \mathrm{~cm} \times 1.4 \mathrm{~cm}$ mobile mass in the right ventricular outflow tract with a possible attachment to the pulmonary valve cusps. There was trace pulmonary regurgitation, but no obstruction of flow. Due to her recent history of melanoma, there was a concern that this may be a metastatic lesion. Head, chest and abdominal computed tomography scans ruled out other metastases. A positron emission tomography scan revealed no focal uptake of 18-fluorodeoxyglucose in the region of the heart. The patient was offered two options: echocardiographic follow-up or surgical resection. She opted to have the tumour resected to end her uncertainty.

An intraoperative transesophageal echocardiogram confirmed the preoperative findings (Figure 1). On opening the pulmonary artery, a gelatinous tumour (Figure 2) attached to the inferior surface of the right posterior pulmonary cusp was found and excised with ease, sparing the valve cusp. A frozen section revealed a typical PFE with multiple papillary excrescences of fibrocollagenous tissue covered by endothelial cells (Figure 3). A repeat transesophageal echocardiogram revealed good pulmonary valve function. The postoperative course was uneventful.

\section{DISCUSSION}

PFEs are the third most common primary cardiac tumours after atrial myxomas and lipomas, accounting for approximately $7 \%$ of cases (1) and representing $70 \%$ to $80 \%$ of heart valve tumours (1,2). PFEs arise from valvular endocardium (2) and occur on the atrial side of the atrioventricular valves; however, when the semilunar valve is involved, there is no predilection for one side or the other (2). Formerly thought to be innocuous, they are now known to be capable of producing an obstruction to flow, particularly coronary ostial flow, and are associated with transient ischemic attacks and stroke (1). These tumours have a significant propensity to embolize (2), but rarely cause valvular dysfunction (3). The number of reported cases with PFEs on the right side of the heart is extremely low and before echocardiography, right-sided lesions were typically discovered as incidental findings at postmortem examination. In a literature review by Howard et al (1), one case of PFE on a tricuspid valve presented with a clinical picture of pulmonary embolism. Among the extremely rare cases of pulmonary PFEs reported in literature, there was no correlation between the PFE and symptoms. Therefore, one cannot accurately estimate the risk of embolism at the pulmonary location, but it is a potential risk. There is not enough information on pulmonary valve PFEs to establish guidelines for management. In the present case, the tumour was removed because there was a suspicion that it could have been a melanoma metastasis. As Klarich et al (3) concluded, management issues remain difficult because of the rarity of PFEs and because clinical decisions must be individualized.

Another important issue is whether PFE can be diagnosed with enough certainty using echocardiography. Localizing the mass

\footnotetext{
${ }^{1}$ Division of Cardiac Surgery; ${ }^{2}$ Division of Cardiac Anesthesia, University of Ottawa Heart Institute; ${ }^{3}$ Division of Anatomic Pathology,

Department of Pathology, Ottawa Hospital; ${ }^{4}$ Division of Cardiology, University of Ottawa Heart Institute, Ottawa, Ontario

Correspondence: Dr Moheb Ibrahim, University of Ottawa Heart Institute, 40 Ruskin Street, Ottawa, Ontario K1Y 4W7.

Telephone 613-761-4233, fax 613-761-5367, e-mail mibrahim@ottawaheart.ca

Received for publication June 8, 2005. Accepted July 21, 2005
} 


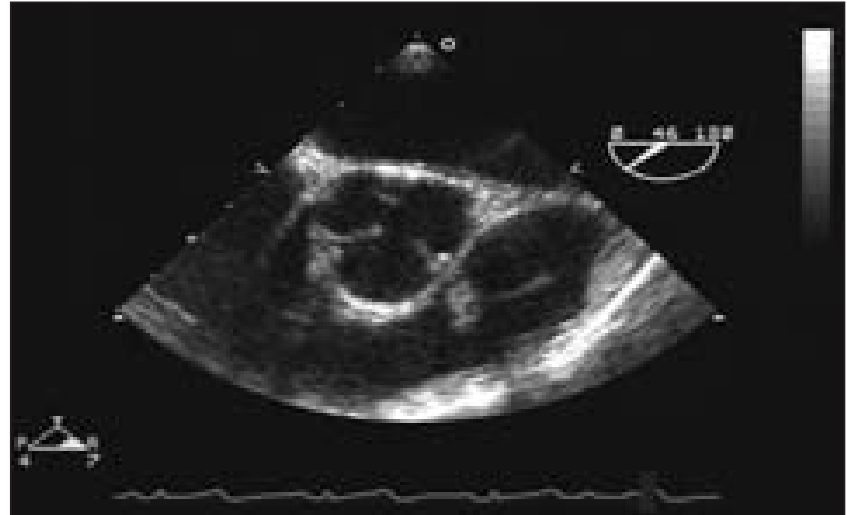

Figure 1) An intraoperative transesophageal echocardiogram showing a mass related to a pulmonary valve cusp

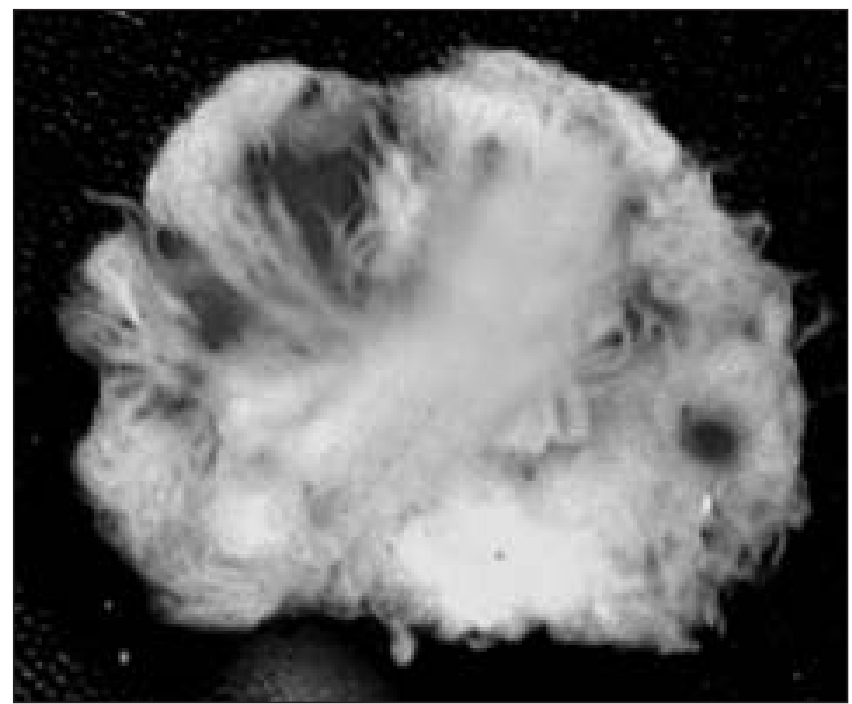

Figure 2) Macroscopic appearance of the pulmonary papillary fibroelastoma after resection

to the valve rather than the myocardium favoured PFE over melanoma metastasis. Klarich et al (3) indicated that the most characteristic ultrasound features that identify a tumour as a PFE are small size (usually less than $1.5 \mathrm{~cm}$ ), pedicle or stalk attachment to the endocardium (with high mobility), refractive appearance and, often, areas of echolucency within the

\section{REFERENCES}

1. Howard RA, Aldea GS, Shapira OM, Kasznica JM, Davidoff R. Papillary fibroelastoma: Increasing recognition of a surgical disease. Ann Thorac Surg 1999;68:1881-5.

2. Edwards FH, Hale D, Cohen A, Thompson L, Pezzella AT, Virmani R. Primary cardiac valve tumors. Ann Thorac Surg 1991;52:1127-31.

3. Klarich KW, Enriquez-Sarano M, Gura GM, Edwards WD, Tajik AJ, Seward JB. Papillary fibroelastoma: Echocardiographic characteristics for diagnosis and pathologic correlation. J Am Coll Cardiol 1997;30:784-90.

4. Schwinger ME, Katz E, Rotterdam H, Slater J, Weiss EC, Kronzon I.

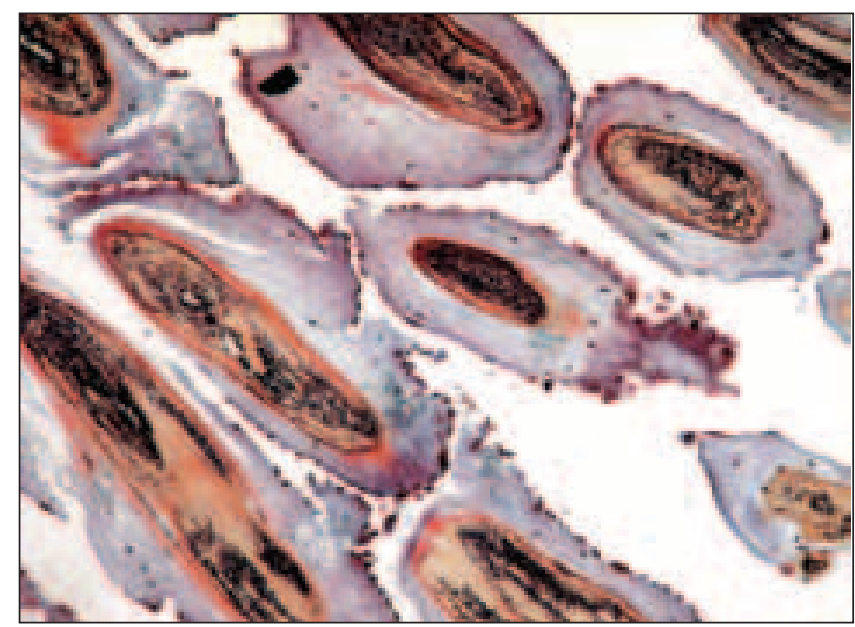

Figure 3) Photomicrograph of the papillary fibroelastoma showing numerous fronds of collagen with dark black elastic cores. The fronds are covered with endothelium (Movat pentachrome stain, original magnification $\times 200$ )

tumour. The patient in the present case exhibited only some of these features, thus, we could not make a definitive diagnosis of PFE. Myxoma can usually be distinguished from PFE by its location, being atrial in the great majority of cases.

Schwinger et al (4) reported the use of percutaneous transvenous biopsy of a right atrial PFE. However, a biopsy could induce fragmentation and embolization of the tumour. The use of 18-fluorodeoxyglucose positron emission tomography scan to diagnose melanoma is useful, but, unfortunately, has a sensitivity and specificity of only $74 \%$ and $86 \%$, respectively (5).

In a report by Bhagwandien et al (6), the PFE was excised along with most of the pulmonary valve leaflet. This was followed by pulmonary valve repair with a semicircular piece of autologous unpreserved pericardium. We think that if resection of the tumour looks adequate, then the pulmonary valve leaflet should be left intact.

\section{CONCLUSION}

PFE of the pulmonary valve is rare. Preoperative diagnosis remains evasive unless certain echocardiographic features are fulfilled. The management of these patients should be individualized, taking into consideration the necessity of making an accurate tissue diagnosis in certain cases. The related valve cusps can be spared, but careful follow-up is recommended.

Right atrial papillary fibroelastoma: Diagnosis by transthoracic and transesophageal echocardiography and percutaneous transvenous biopsy. Am Heart J 1989;118:1047-50.

5. Fuster D, Chiang S, Johnson G, Schuchter LM, Zhuang H, Alavi A Is $18 \mathrm{~F}-\mathrm{FDG}$ PET more accurate than standard diagnostic procedures in the detection of suspected recurrent melanoma? J Nucl Med 2004;45:1323-7.

6. Bhagwandien NS, Shah N, Costello JM Jr, Gilbert CL, Blankenship JC. Echocardiographic detection of pulmonary valve papillary fibroelastoma. J Cardiovasc Surg (Torino) 1998;39:351-4 